\title{
Identification of Estrogen-Related Genes in Breast Cancer: The Malaysian Context
}

\author{
Zubaidah Zakaria ${ }^{*}, 1$, Ivyna Bong Pau Ni ${ }^{1}$, Prashanth Bagali ${ }^{2}$, Rohaizak Muhammad ${ }^{3}$, \\ Norlia Abdullah ${ }^{3}$, Naqiyah Ibrahim ${ }^{3}$, Nor Aina Emran ${ }^{4}$, Noor Hisham Abdullah ${ }^{5}$ and \\ Sharifah Noor Akmal Syed Hussain ${ }^{6}$
}

\author{
${ }^{I}$ Haematology Unit, Cancer Research Centre, Institute for Medical Research, Malaysia \\ ${ }^{2}$ GENEFLUX Biosciences Sdn. Bhd., Suite\#G1, Menara KLH, Bandar Puchong Jaya, Malaysia \\ ${ }^{3}$ Department of Surgery, Faculty of Medicine UKM, Malaysia \\ ${ }^{4}$ Department of General Surgery, Kuala Lumpur Hospital, Malaysia \\ ${ }^{5}$ Department of Surgery, Breast and Endocrine Surgery, Putrajaya Hospital, Malaysia \\ ${ }^{6}$ Department of Pathology, Faculty of Medicine UKM, Malaysia
}

\begin{abstract}
Estrogen receptor (ER) status is an important indicator used to predict hormone responsiveness and survival rate of breast cancer patients. Breast cancer patients with estrogen receptor positive $(\mathrm{ER}+)$ tumors are more likely to benefit from endocrine therapies and have better prognosis than those with estrogen receptor negative (ER-) tumors. Approximately $30 \%$ of the patients with ER+ phenotype do not benefit from anti-estrogen therapies. This circumstance suggests that additional biomarkers are needed to predict and improve the treatment strategies in breast cancer patients. We analyzed $28 \mathrm{ER}+$ and $18 \mathrm{ER}$ - tumors to evaluate their gene expression patterns. We identified 180 differentially expressed genes in ER+ compared to the ER-group at 99\% confidence interval level. Out of the 180 genes, 79 and 94 genes were determined respectively as positive and negative significant genes in Significance Analysis of Microarray (SAM). Eleven out of the 79 significant positive genes were more than two $(>2)$ fold change. The differentially expressed genes identified in the ER+ group included CADM4, CD151, GATA3, Wnt2, PGR, TFF1 and TFF3. We randomly selected two genes, namely CD151 and LPIN1 for verification by Taqman qRT-PCR. Our qRT-PCR result is reproducible and comparable with the microarray data. Our preliminary findings revealed potential estrogen-responsive genes such as CADM4, CD151 and GATA3, which might play a crucial role in ER+ breast cancer development and progression in the Malaysian population. More extensive studies are however needed to investigate the role of these genes in the carcinogenesis of estrogen related breast cancers.
\end{abstract}

Keywords: Estrogen receptor, breast cancer, differentially expressed genes, estrogen-responsive genes.

\section{INTRODUCTION}

A total of 67,792 new cancer cases were diagnosed in Malaysia over a span of three years (2003-2005). The cumulative life time risk for any Malaysian to develop cancer accounts for $14.8 \%$ in males and $15.9 \%$ in females [1]. This translates to an estimated risk of one in every seven males and one in every six females developing cancer during their lifetime. Breast cancer accounts for the majority of the cancers detected among women in Malaysia. It has an overall incidence of $18 \%$ among the total number of cases reported in the three major ethnic groups, that is, the Malays, Chinese and Indian women [1].

Estrogen, the female signaling molecule plays a crucial role in the development and maintenance of female characteristics and sexual reproduction. Although estrogen is an important regulator of growth and differentiation in

*Address correspondence to this author at the Institute for Medical Research, Jalan Pahang, 50588 Kuala Lumpur, Malaysia; Tel: +603 26162708; Fax:+603 26162707; E-mail: zubaidah@imr.gov.my normal mammary gland, it can also trigger the onset of breast cancer through the abnormal expression of estrogenresponsive genes. Patients with estrogen receptor positive $(\mathrm{ER}+)$ breast tumors have been found to have a more favorable prognosis than those with estrogen receptor negative (ER-) tumors [2]. These patients respond well to hormonal therapies. To date, there are scanty research reports on the identification of hormone responsive gene set responsible for monitoring the hormone signaling status and application of the information to subtype breast tumors according to functional phenotype. The gene expression profiles of ER+ tumor have been shown to be different from the ER- tumors $[3,4]$. These reports implicate that the ER status of breast cancer represents a distinct phenotype. Although numerous studies have been performed, the details of the estrogen effect on downstream gene targets, the role of co-factors, and cross-talk between other signaling pathways are not completely understood [5]. In fact, epidemiology evidence had shown that the risk of breast cancer predisposition is varies among different ethnicity [6]. This study aims to determine the gene expression patterns in 
relation with ER status in a group of multi ethnic Malaysian breast cancer patients. Proper identification of new genes or pathways responsive to estrogen could lead to a better understanding on estrogen related breast tumorigenesis and then improvement in the diagnosis and treatment of the disease.

\section{MATERIALS AND METHODOLOGY}

\section{Breast Tumor Biopsies}

Tumor and normal tissues samples from 46 female patients diagnosed with primary local breast carcinoma were analyzed for gene expression profiling using Affymetrix GeneChip Human Genome U133A array, which contains 22,283 probe sets representing $\sim 18,400$ different genes. Breast cancer patients were recruited from Hospital Kuala Lumpur, Hospital Universiti Kebangsaan Malaysia and Hospital Putrajaya. Samples were grossly dissected in the operating theater immediately after surgical excision and were flash-frozen in liquid nitrogen prior to RNA isolation.

Breast cancer carcinomas were investigated from 46 tumor samples, amongst which 37 and 9 patients had infiltrating ductal carcinoma (IDC) and non-infiltrating ductal carcinoma, respectively. All the subjects had undergone surgery for breast cancer from the year 20052007. Out of 46 cases, 9, 24, 13 patients were classified as Grade 1, Grade 2 and Grade 3, respectively.

The study subjects represented three major ethnic races of the Malaysian population, which consisted of 30 Malay, 10 Chinese and 6 Indian individuals. The patient's age ranged between 22-79 years (mean age - 51.37 years, median - 52 years and mode - 47 years). Twenty-eight patients or $60 \%$ of the total subjects in this study were ER+ and 18 were found to be ER-. Ethical approval was obtained from the Medical Research \& Ethics Committee, Ministry of Health Malaysia to perform this study. The informed consent was obtained from the study participants in written format.

\section{RNA Isolation}

Poly-L-Lysine coated slide was prepared for a Diff Quick Staining (Imeb Inc.) for all tissues. Microscopic examination of touch preparations verified the presence of at least $70 \%$ of cancer cells in all tumor samples. Minced tissues were placed directly in Trizol Reagent (Invitrogen), homogenized and total RNAs were isolated and purified through RNeasy columns (QIAGEN) according to the manufacturer's instructions. The integrity of the purified total RNAs were assessed by visualization of the $28 \mathrm{~S} / 18 \mathrm{~S}$ ribosomal RNAs ratio on $1 \%$ agarose denaturing gel and the quantities were assessed based on absorbance at $260 \mathrm{~nm}$ in Biophotometer (Eppendorf).

\section{Microarray Labeling and Hybridization}

One hundred micrograms of purified total RNA was labeled using two cycle cDNA synthesis kit and 35 micrograms of cRNAs were hybridized onto Affymetrix GeneChip HG-U133A according to manufacturer's recommendations. After the chips were washed and stained in fluidic station 400, the chips were scanned with Gene Array scanner 2500. Hybridization signals were scaled in the Affymetrix GCOS software version 1.4 prior to analysis by adjusting global trimmed mean signal intensity value to ensure the scale factors were in the range of $1.000-3.000$.

\section{Statistical Analysis}

The microarray data analysis of Affymetrix GeneChip HG U133A array was carried out using the TM4 suite [7]. We applied total intensity normalization to analyze the microarray data. Differential expression of genes in the expression profiles of microarray was detected using Student's $t$-test. To compare ER+ and ER- groups, which consisted of unequal number of tumor tissue samples, we applied between subjects $t$-test. Two test statistic or level of significance to differentiate significant and non significant genes was applied. Probability value of 0.01 was used as test criteria or significance criteria. If the calculated $p$-value for a gene was less than or equal to the user input alpha (critical pvalue), the gene was considered to be significant $(p \leq 0.01)$.

We applied two class paired Significance Analysis of Microarrays (SAM) test to pick out significant genes based on differential expression between the study groups. SAM gives estimates of the False Discovery Rate (FDR), which is the proportion of genes likely to have been wrongly identified by chance as being significant.

\section{Quantitative Real-Time Polymerase Chain Reaction (qRT-PCR)}

The concentration of the RNA samples was determined using the NanoDrop ND-1000 Spectrophotometer (NanoDrop Technologies Inc.). One - two hundreds $\mu \mathrm{g}$ of total RNAs were reverse-transcribed using AMV and the random hexamer primer (First strand cDNA synthesis kit, Roche). Real-time RT-PCR was performed using Taqman probe. Probes for GAPDH (cat. no.: 04688589001), CD151 (cat. no.: 04688660001) and LPIN1 (cat. no.: 04688031001) were purchased from Universal ProbeLibrary (Roche Diagnostics) and the primers were synthesized from Bioneer. Due to limitation in the samples, verification test for CD151 and LPIN1 were conducted with 45 (27 ER+ and 18 ER-) and 40 samples (25 ER+ and 15 ER-), respectively. The primer sequences for GAPDH, CD151 and LPIN1 were listed in Table $\mathbf{1}$.

Table 1. Primer Sequences for qRT-PCR

\begin{tabular}{|c|c|c|}
\hline Gene & Size Amplicons (nt) & 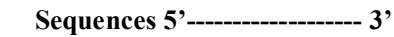 \\
\hline \multirow{2}{*}{ GAPDH } & \multirow{2}{*}{112} & Forward ctctgetcctcetgttcgac \\
\hline & & Reverse acgaccaaatccgttgactc \\
\hline \multirow{2}{*}{ CD151 } & \multirow{2}{*}{107} & Forward ctgcgectgtacttcatcct \\
\hline & & Reverse ttctccttgagactccgtgtt \\
\hline \multirow{2}{*}{ LPIN1 } & \multirow{2}{*}{104} & Forward tgggtgtttgcaatacaaagg \\
\hline & & Reverse gctccttcacggtgacaaa \\
\hline
\end{tabular}

Standard curves for CD151, LPIN1 and GAPDH were generated using $10 \mathrm{X}$ serial diluted purified target PCR products synthesized from normal breast total RNAs. Realtime PCR was carried out in $20 \mu \mathrm{L}$ volumes containing $4 \mu \mathrm{g}$ of cDNA, 1X LightCycler ${ }^{\circledR}$ LC480 Probe Master, $2 \mu \mathrm{L}$ of probes and 0.8 - 1.0 pmol of each primer. Real-time PCR 
was carried out on LightCycler LC480 using 96 well plate in duplicate. The amplification program consisted of preincubation at $95{ }^{\circ} \mathrm{C}$ with a 10 min hold, denaturation at 95 ${ }^{\circ} \mathrm{C}$ with a $10 \mathrm{~s}$ hold, followed by annealing at $54{ }^{\circ} \mathrm{C}$ with a $10 \mathrm{~s}$ hold $\left(40\right.$ cycles) and extension at $72^{\circ} \mathrm{C}$ with a $1 \mathrm{~s}$ hold. A water control was included in each run as negative control. Gene expressions of the samples were obtained by comparing the crossing points (Cp) with the log concentrations of standard curves. The obtained gene expression or concentration of the gene was then normalized with GAPDH. The ratio of mRNA expression of CD151 and LPIN1 in ER+ breast tumors $v s$ ER- breast tumors were calculated based on the mean expression of the genes in ER+ and ER-groups.

\section{RESULTS}

A total of 181 significant differentially expressed probes or 180 differentially expressed genes were identified between ER+ and ER- group at 99\% confident interval level [Supplementary 1]. In the SAM analysis, 174 probes out of 181 probes are significant. Seventy nine and 95 probes were significant positive and negative in ER+ tumors, respectively (Fig. 1). Seventy nine positive significant probes and 95 negative significant probes were derived from 79 and 94 genes, respectively. Eleven out of 79 significant positive probes showed $>2$ fold change (Table 2). They were LGALS8, ABCA3, SCCPDH, RABEP2, EFHC1, ACOT1 \& ACOT2, NOVA1, CADM4, CD151, DCI and TFF3. None of the significant negative probes showed $>2$ fold change.
Table 2. Mean Intensities and Fold Change Values of 11 Significant Positive Probes Identified with SAM Analysis

\begin{tabular}{|c|c|c|c|}
\hline Gene & $\begin{array}{c}\text { Mean } \\
\text { Intensity } \\
\text { (ER-) }\end{array}$ & $\begin{array}{c}\text { Mean } \\
\text { Intensity } \\
\text { (ER+) }\end{array}$ & $\begin{array}{c}\text { Fold } \\
\text { Change } \\
\text { (ER+/ ER-) }\end{array}$ \\
\hline \hline LGALS8 & -3.6456 & -2.8436 & 2.6233 \\
\hline ABCA3 & -3.3564 & -2.4405 & 2.2010 \\
\hline SCCPDH & -1.6983 & -0.7298 & 2.1010 \\
\hline RABEP2 & -3.4750 & -2.5494 & 2.1680 \\
\hline EFHC1 & -2.2806 & -1.5181 & 2.0465 \\
\hline ACOT1 / ACOT2 & -3.5013 & -2.5120 & 3.0619 \\
\hline NOVA1 & -6.0406 & -4.6487 & 5.0627 \\
\hline CADM4 & -5.1421 & -4.2402 & 2.1417 \\
\hline CD151 & -3.2489 & -2.3142 & 2.0915 \\
\hline DCI & -2.6556 & -1.900 & 2.0033 \\
\hline TFF3 & -0.6427 & 0.5047 & 2.9876 \\
\hline
\end{tabular}

The standard curves for CD151, LPIN1 and GAPDH were successfully obtained (Figs. 2a-d, 3a-d). The PCR amplification efficiencies for CD151 and GAPDH genes were 1.674 and 1.758 , respectively while PCR efficiencies for LPIN1 and GAPDH genes were 1.921 and 1.843,

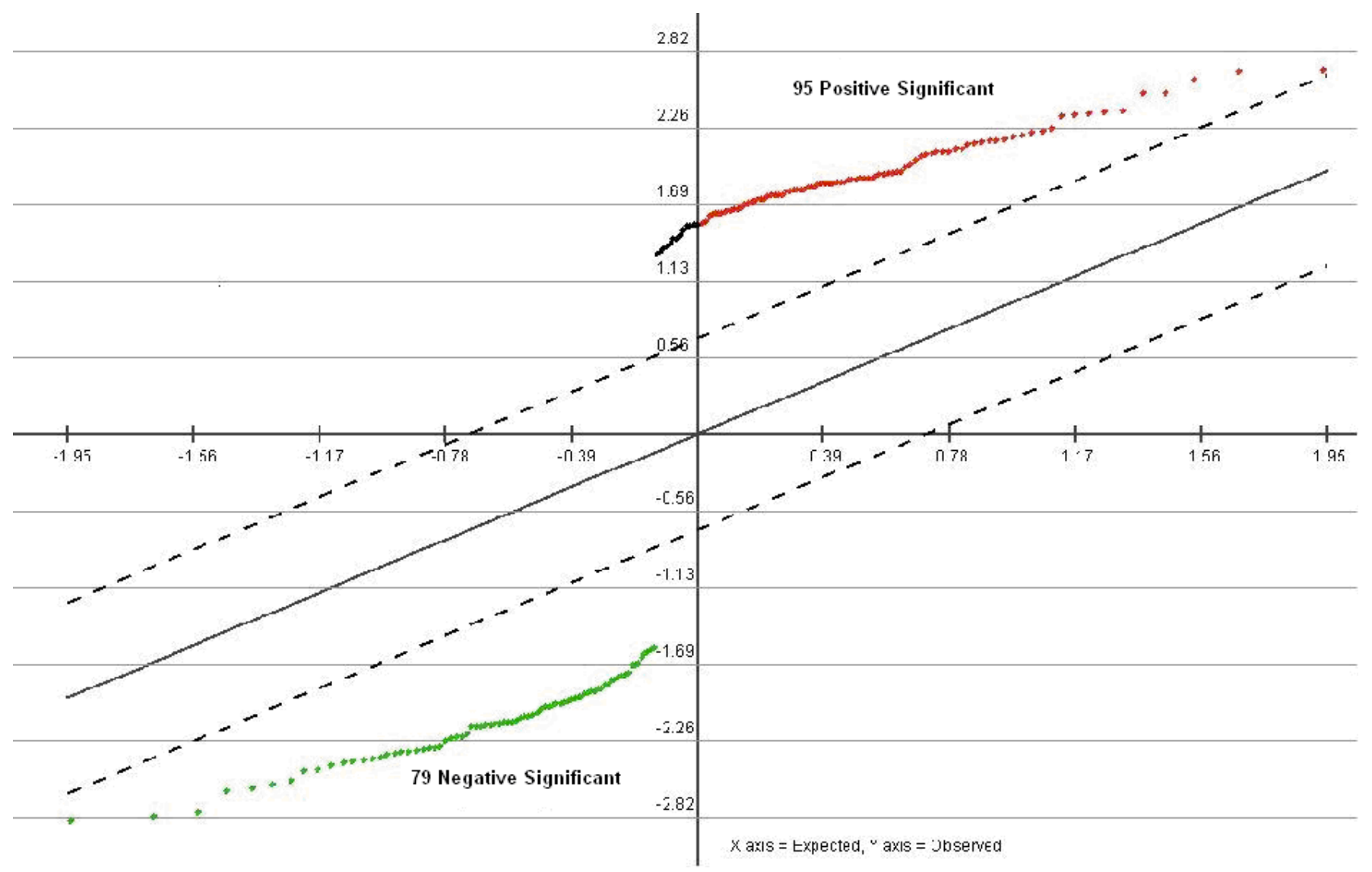

Fig. (1). Graphical representation of the Significance Analysis of Microarray (SAM) of 181 significantly expressed probes between ER+ and ER- groups $(\mathrm{p} \leq 0.01)$. Red colored dots represent positive significant probes and green colored dots represent negative significant probes. 


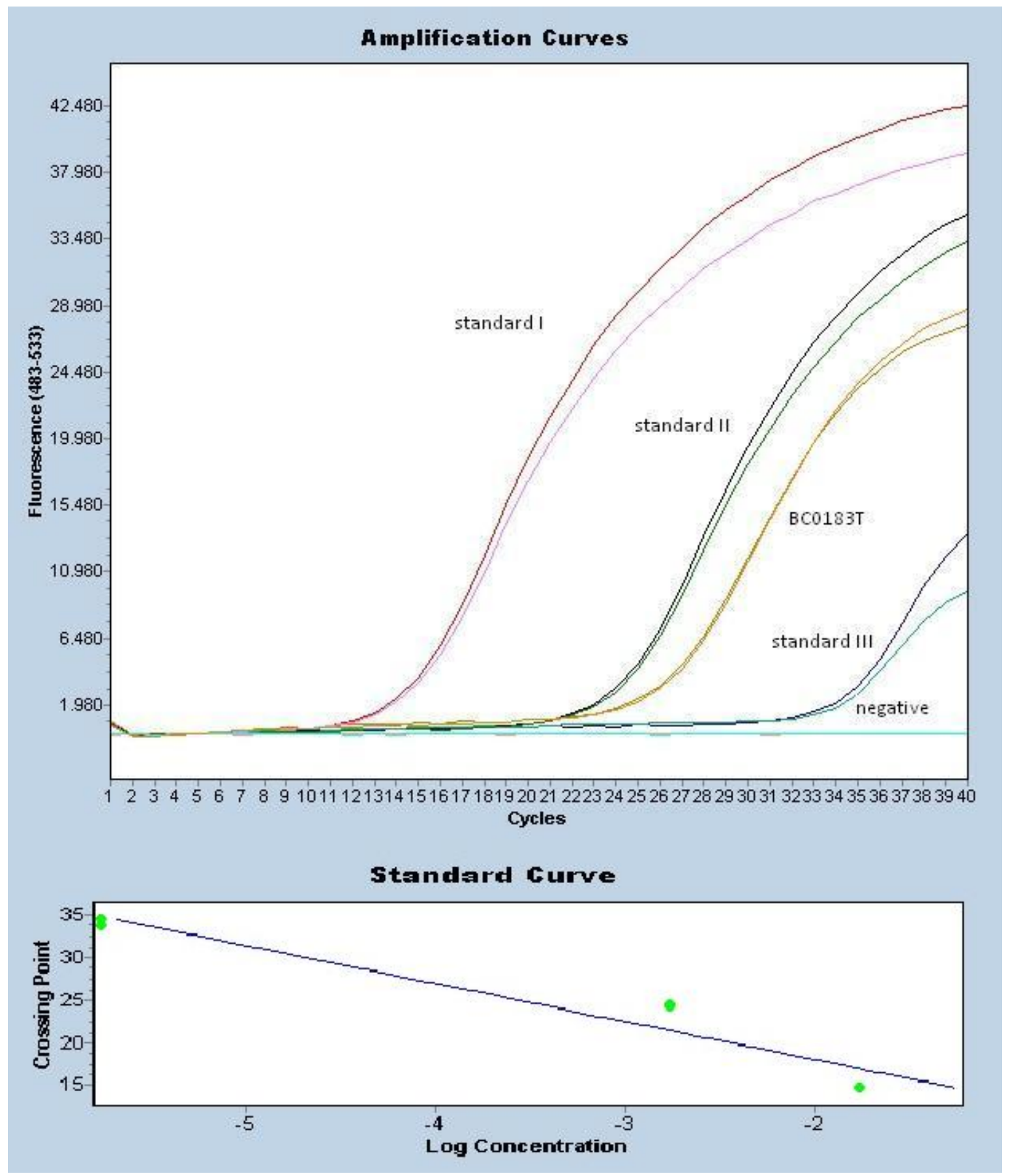

Fig. (2). (a) Amplification curves for CD151 standard by using serial diluted purified target PCR products (The standard curves contained $1.74 \times 10^{-2} \mathrm{ng}, 1.74 \times 10^{-3} \mathrm{ng}$ and $1.74 \times 10^{-6} \mathrm{ng}$ of cDNAs). Amplification curves for sample designated as BC0183T and negative control were included in this graph. All samples were performed in duplicate. (b) The standard curve was imported to create the scatter plot of log concentration $v s$ crossing point with PCR efficiency of 1.674.

respectively. The qRT-PCR results showed that the expressions of CD151 and LPIN1 were consistent with the microarray data. The expression of CD151 and LPIN1 were significantly up-regulated and down-regulated by 1.577 fold and 0.684 fold, respectively in ER+ group relative to ERgroup. The mean expression of CD151 and LPIN1 for ER+ and ER- groups were shown in Table 3. As expected, the expression ratio of CD151 and LPIN1 in ER+vs ER- group were slightly different from microarray result since qRTPCR is more sensitive than microarray.

\section{DISCUSSION}

The ER is an important bio-marker in the therapeutic target and prognostic prediction of breast cancer patients. ER+ tumors exhibit a well-differentiated phenotype and respond more effectively to endocrine treatment [8, 9]. Therefore, it has better survival rate and lower risk of any recurrence. Although ER has been considered as a useful determinant in predicting response in endocrine therapies, approximately $30 \%$ of ER+ tumors are resistant to hormonal 


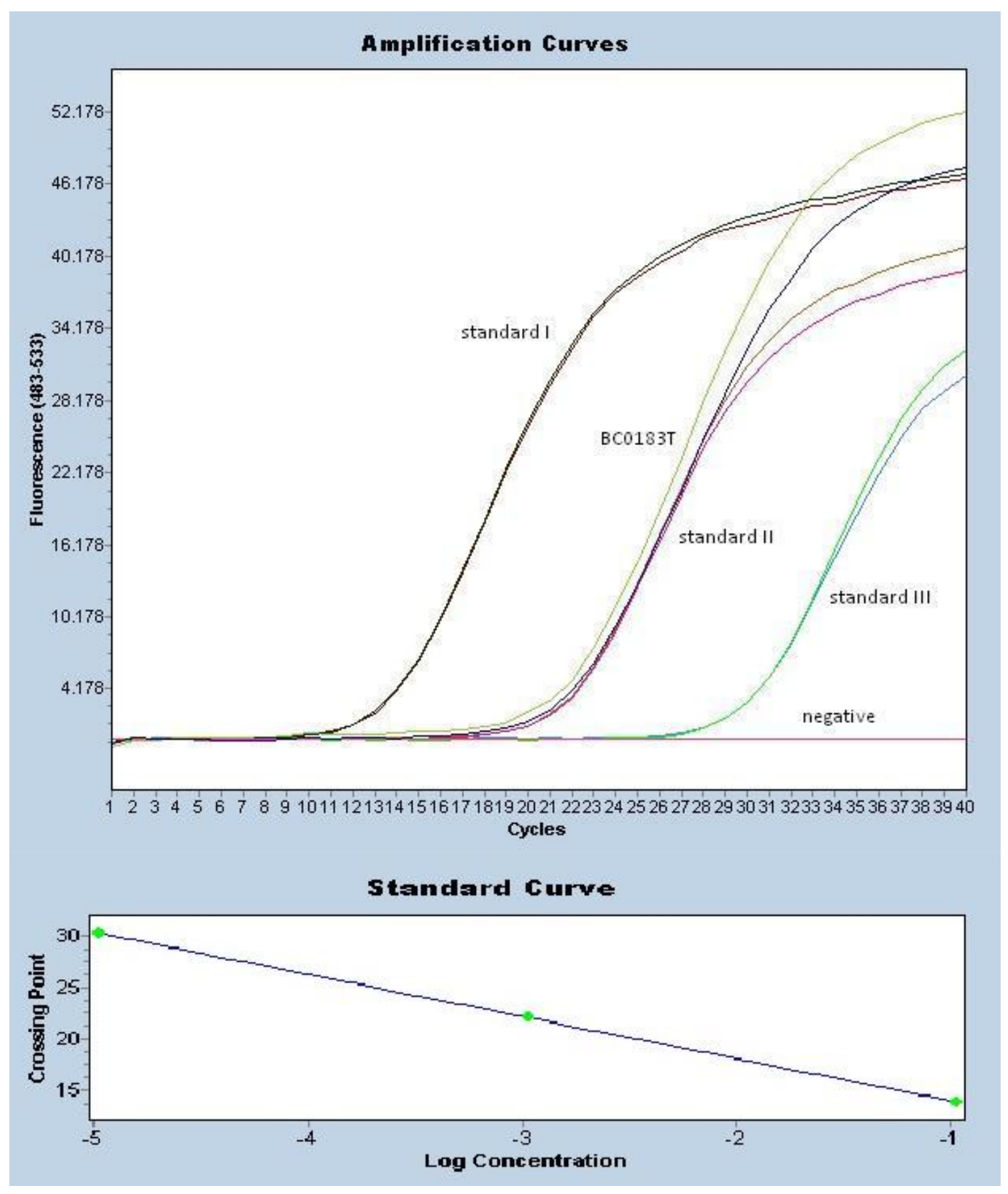

Fig. (2). (c) Amplification curves for internal control gene, GAPDH for normalization with CD151 expression. GAPDH standards were obtained by serial diluted purified target PCR products (The standard curves contained $1.06 \times 10^{-1} \mathrm{ng}, 1.06 \times 10^{-3} \mathrm{ng}$ and $1.06 \times 10^{-5} \mathrm{ng}$ of cDNAs). Amplification curves for sample designated as BC0183T and negative control were included in this graph. All samples were performed in duplicate. (d) The standard curve was imported to create the scatter plot of log concentration $v s$ crossing point with PCR efficiency of 1.758 .

therapies or estrogen deprivation therapies [10]. The percentage of patient response to endocrine therapy varies between different $\mathrm{ER}$ and $\mathrm{PR}$ status. The response in endocrine therapy in $\mathrm{ER}+/ \mathrm{PR}+, \mathrm{ER}+/ \mathrm{PR}-, \mathrm{ER}-/ \mathrm{PR}+$ and ER-/ PR- are $78 \%, 34 \%, 45 \%$ and $10 \%$, respectively [11]. The reasons for this scenario are still unknown. Hence, ER status alone is insufficient to serve as a predictive biomarker for breast cancer endocrine therapy. Additional genes involved in the molecular genetics of ER-dependent breast cancer are yet to be determined.
Our results revealed a set of 180 differentially expressed genes, which showed a distinct pattern of expression between ER+ and ER- tumors $(p \leq 0.01)$. These genes are involved in various functional categories such as cell adhesion molecule, signal transduction, cell cycle regulation, transcription factor, cell proliferation and metabolic processes. As expected, PGR and TFF1 were identified as up-regulated genes in ER+ breast tumors [12]. Besides ER, PGR and TFF1 were the two most useful predictive biomarkers for breast cancer endocrine therapy [13]. The 


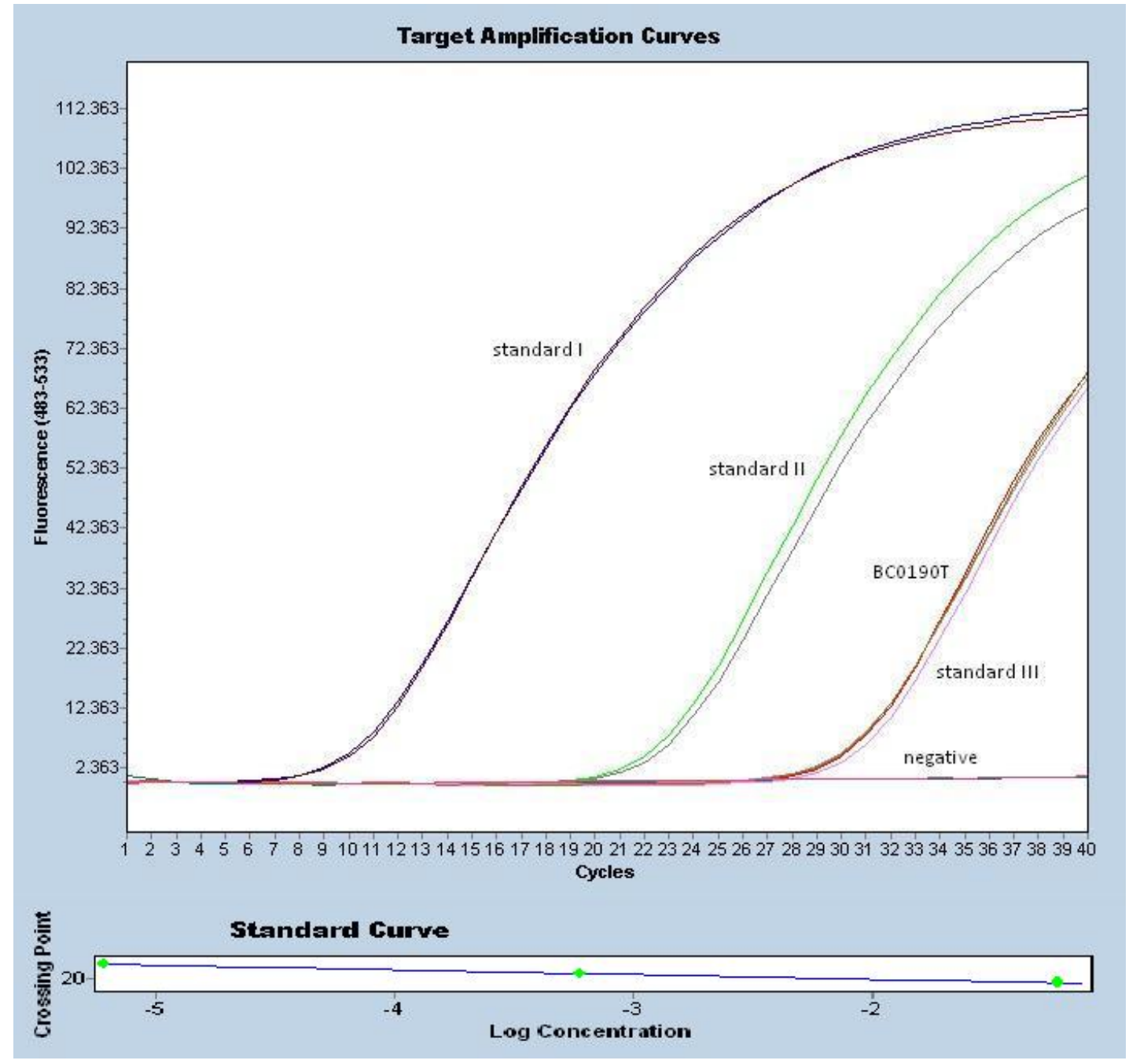

Fig. (3). (a) Amplification curves for LPIN 1 standard by using serial diluted purified target PCR products (The standard curves contained $6.00 \times 10^{-2} \mathrm{ng}, 6.00 \times 10^{-3} \mathrm{ng}$ and $\left.6.00 \times 10^{-5} \mathrm{ng} \mathrm{cDNAs}\right)$. Amplification curves for sample designated as BC0190T and negative control were included in this graph. All samples were performed in duplicate. (b) The standard curve was imported to create the scatter plot of log concentration $v s$ crossing point with PCR efficiency of 1.921.

discovery of PGR has improved the predictive value of ER status. Although TFF1 is a well established breast cancer biomarker, the use of TFF1 in predicting prognosis in hormonal therapies is still under research [14].

Consistent with previous findings, another trefoil factor gene, TFF3 is up-regulated in ER+ breast tumors [13]. TFF3 has been initially linked to the cancers of the gastrointestinal tract [15]. In vitro studies showed that TFF3 is expressed in $\mathrm{ER}+$ breast cancer cell lines. This gene is believed to play a crucial role in cell migration by regulating the expression and cellular localization of APC and E-cadherin-catenin complexes $[15,16]$.

LGALS8, ABCA3, SCCPDH, RABEP2, EFHC1, ACOT1 \& ACOT2, NOVA1, CADM4, CD151, DCI and TFF3 were identified as significant over-expressed genes by $>2$ fold change in ER+ breast tumors. We compared these genes with five published microarray studies examining breast tumor cases from the Oncomine database [17-21]. Our findings revealed that all the genes except CADM4 were reported as significant over-expressed genes in these studies.
CADM4 is a cell adhesion molecule, the alteration of which might disrupt the intercellular contact of cells and lead to the local invasion and spreading of tumor cells [22]. However, the mechanism underlying the role of CADM4 in the tumorigenesis of estrogen-dependent breast cancer is not well understood.

Besides CADM4, other cell adhesion molecules identified in ER+ breast tumors were MCAM and CD151. The role of CD151 gene in cell motility highlighted its function as a promoter in the tumor progression and metastasis events [23]. Over-expression of CD151 was found to be associated with poor prognosis in non-small cell carcinoma of the lung, colon and prostate [24-26]. In breast cancer, $C D 151$ is elevated in approximately $31 \%$ of the cases and it is significantly related to the high-grade $(40 \%)$ and estrogen receptor negative (45\%) subtypes [27]. Reduced CD151 expression is likely to cause delay in tumor cell progression [27]. Our gene expression data showed that CD151 was over-expressed in ER+ breast subtype, which is contradictory with previous research findings. This scenario might be caused by the different cell type and extracellular 


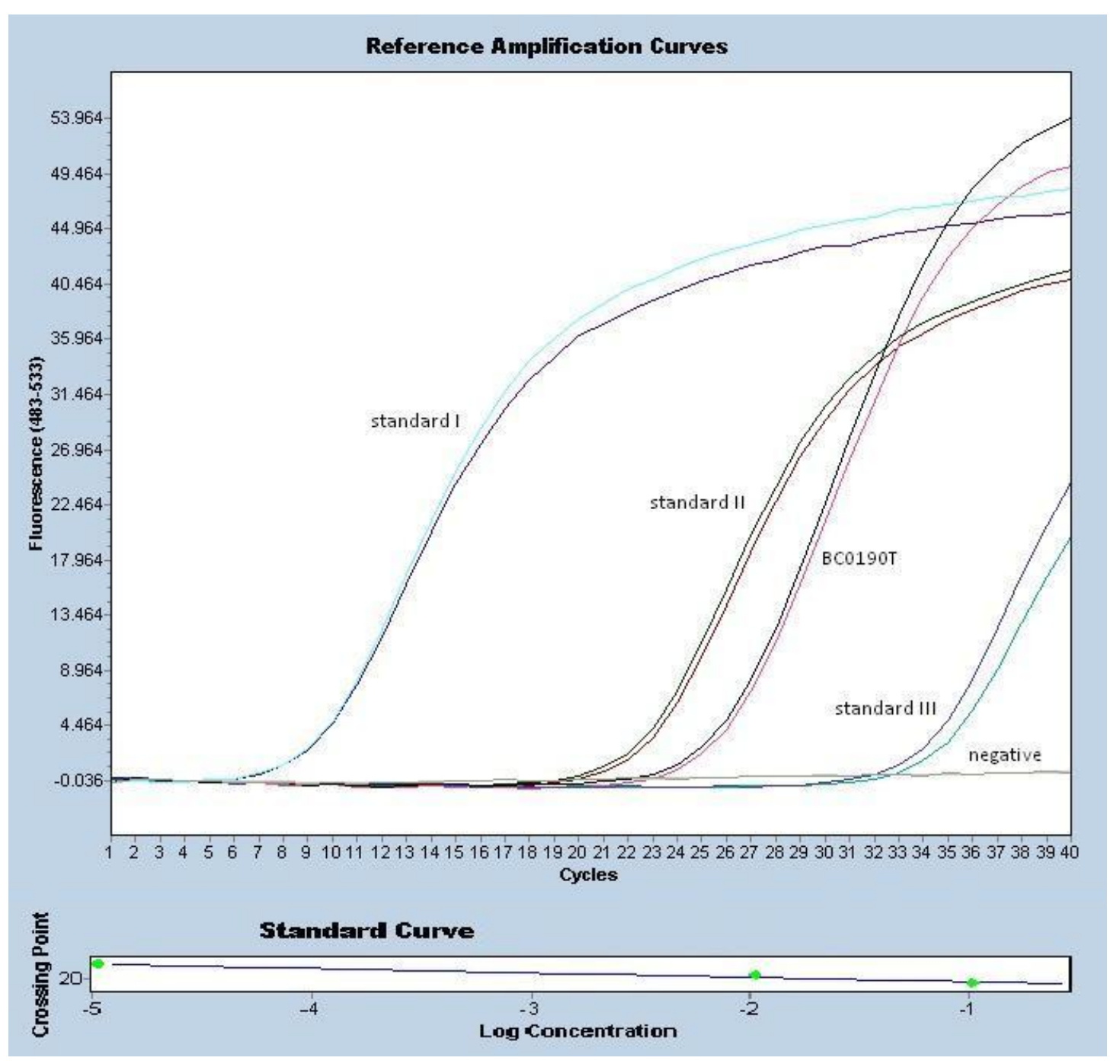

Fig. (3). (c) Amplification curves for internal control gene, GAPDH for normalization with LPIN 1 expression. GAPDH standards were obtained by serial diluted purified target PCR products (The standard curves contained $1.06 \mathrm{x} 10 \mathrm{ng}, 1.06 \mathrm{x} 10^{-2} \mathrm{ng}$ and $1.06 \mathrm{x} 10^{-4} \mathrm{ng}$ of cDNAs). Amplification curves for sample designated as BC0190T and negative control were included in this graph. All samples were performed in duplicate. (d) The standard curve was imported to create the scatter plot of log concentration vs crossing point with PCR efficiency of 1.843 .

matrix components of the breast tumor cells and the expression of the integrin alpha3 betal gene in the cells [27].

Table 3. Comparison of Microarray and qRT-PCR Results in ER+ and ER- Breast Cancers. The qRT-PCR Results Showed that CD151 and LPIN1 Were OverExpressed and Under-Expressed, Respectively in ER+ Breast Cancer and they were Reproducible with Microarray Results

\begin{tabular}{|c|c|c|c|c|}
\hline Gene & Experiment & $\begin{array}{c}\text { ER+ } \\
(\text { Mean })\end{array}$ & $\begin{array}{c}\text { ER- } \\
\text { (Mean) }\end{array}$ & $\begin{array}{c}\text { Ratio } \\
\text { ER+/ER- }\end{array}$ \\
\hline \hline CD151 & Microarray & -2.314 & -3.249 & 0.712 \\
\hline & qRT-PCR & 0.304 & 0.193 & 1.577 \\
\hline LPIN1 & Microarray & 0.216 & 0.508 & -0.426 \\
\hline & qRT-PCR & 0.00522 & 0.00763 & -0.684 \\
\hline
\end{tabular}

Wnts belong to a large family of cysteine-rich secreted glycoproteins, consisting of at least 19 members in humans [28-30]. Wnts play important roles in multiple cellular processes during development, including migration, apoptosis, polarity, differentiation and stem cell self-renewal [31]. Wnt2 is a proto-oncogene implicated in the canonical or beta-catenin pathway. Differential expression of Wnt2 is detected in various carcinomas involving breast, stomach and colon $[32,33]$. Our SAM results showed that Wnt2 is significantly up-regulated in ER- breast tumors. Upregulation of Wnt 2 could activate up to $60 \%$ of downstream components in beta-catenin signaling pathway [34]. The activation of downstream target genes in beta-catenin signaling pathway such as cyclin D1, c-myc and AXIN is believed to promote tumorigenesis in mammary glands [31].

Interestingly, our results differ from past research reports which postulated that $\mathrm{Wnt} 2$ is up-regulated in estrogen- 
dependent tumors [33]. We suggest that differential expression of Wnt2 may or may not relate to the hormone estrogen. The downstream effect of down-regulation of Wnt2 in the presence of estrogen hormone is unknown. It probably involves inactivation of certain tumor suppressor genes or apoptosis related genes.

GATA3 is identified as a positive significant gene in ER+. The GATA3 is a potential tumor marker in breast cancer and its expression is strongly correlated with ER + breast tumors [35]. Over-expression of GATA3 is likely to regulate genes, which are critical in the estrogenresponsive breast cancer phenotype. Besides ER, GATA3 has been suggested as a potential indicator for the hormone responsiveness in breast cancer patients. Hence, more extensive functional study of GATA3 in breast cancer is important to delineate the role of GATA3 pathway in oncogenesis of breast cancer.

We randomly selected 2 differentially expressed genes, CD151 and LPIN1 to validate by qRT-PCR. Our qRT-PCR results were consistent with the microarray data. This further indicated that our microarray data was reproducible and reliable.

To the best of our knowledge, this study is the first of its kind to report on gene expression study of estrogen receptor status in multi races of Malaysian breast cancer patients. A total of 180 potential genes that may explain the phenotype differences seen in ER+ and ER- tumors were identified. We conclude that differential expression of CADM4, CD151 and GATA3 might be important and therefore require further investigation to determine their role in the carcinogenesis of estrogen-dependent breast tumors. Identification of CADM4, CD151 and GATA3 would contribute to the understanding of genes involved in the estrogen-dependent carcinogenesis pathway, and improved the diagnosis of breast carcinoma thereby helping in the course of treatment.

\section{ABBREVIATIONS}

$$
\begin{aligned}
& \mathrm{ER} \quad=\text { Estrogen receptor } \\
& \text { PGR }=\text { Progesterone receptor } \\
& \text { TFF } 1=\text { Trefoil factor } 1 \\
& \text { TFF3 = Trefoil factor } 3 \text { (intestinal) } \\
& \mathrm{APC}=\text { Adenomatous polyposis coli } \\
& \text { LGALS8 = Lectin, galactoside-binding, soluble, } 8 \\
& \text { (galectin 8) } \\
& \text { ABCA3 = ATP-binding cassette, sub-family A ( } \mathrm{ABC} 1) \text {, } \\
& \text { member } 3 \\
& \text { SCCPDH }=\text { Saccharopine dehydrogenase (putative) } \\
& \text { RABEP2 = Rabaptin, RAB GTPase binding effector } \\
& \text { protein } 2 \\
& \text { EFHC1 = EF-hand domain (C-terminal) containing } 1 \\
& \text { ACOT1 = Acyl-CoA thioesterase } 1 \\
& \text { ACOT2 = Acyl-CoA thioesterase } 2 \\
& \text { NOVA1 }=\text { Neuro-oncological ventral antigen } 1 \\
& \text { CADM4 }=\text { Cell adhesion molecule } 4 \\
& \mathrm{CD} 151=\mathrm{CD} 151 \text { molecule (Raph blood group) }
\end{aligned}
$$

DCI = Dodecenoyl-Coenzyme A delta isomerase $(3,2$ trans-enoyl-Coenzyme A isomerase)

Wnt2 = Wingless-type MMTV integration site family member 2

GATA3 = GATA binding protein 3

LPIN1 = Lipin 1

\section{ACKNOWLEDGEMENTS}

This study was funded by grant from the Ministry of Science, Technology and Innovation (MOSTI). We would like to thank the Director General of Health Malaysia for his permission to publish the research findings. We also thank the Director of the Institute for Medical Research for the support in the writing of this paper.

\section{SUPPLEMENTARY MATERIAL}

Supplementary 1: Data showed the mean intensities and standard deviation (ER+ and ER- group), p-value and adjusted p-value for 181 differentially expressed probes identified in this study. Supplementary material can be viewed online at publisher's website along with the article.

\section{REFERENCES}

[1] Lim GCC, Rampal S, Yahaya H, Eds. Cancer incidence in Peninsular Malaysia 2003-2005. The third report of the National Cancer Registry. Malaysia 2008; pp. 33-58.

[2] Sunami E, Shinozaki M, Sim M-S, et al. Estrogen receptor and HER2/neu status affect epigenetic differences of tumor-related genes in primary breast tumors. Breast Cancer Res 2008; 10: R46.

[3] Fan C, Oh, DS, Wessels L, et al. Concordance among geneexpression-based predictors for breast cancer. N Engl J Med 2006; 355: 560-9.

[4] Perou CM, Sørlie T, Eisen MB, et al. Molecular portraits of human breast tumours. Nature 2000; 406: 747-52.

[5] Gruvberger S, Ringner M, Chen Y, et al. Estrogen receptor status in breast cancer is associated with remarkably distinct gene expression patterns. Cancer Res 2001; 61: 5979-84.

[6] Hsiao WC, Young KC, Lin SL, et al. Estrogen receptor-a polymorphism in a Taiwanese clinical breast cancer population: a case-control study. Breast Cancer Res 2004;6(3): R180-6.

[7] Saeed AI, Sharov V, White J, et al. TM4: a free, open-source system for microarray data management and analysis. Biotechniques 2003; 34(2): 374-8.

[8] Ali S, Coombes R. Endocrine-responsive breast cancer and strategies for combating resistance. Nat Rev 2002; 2: 101-12.

[9] Pichon MF, Broet P, Magdelenat $\mathrm{H}$, et al. Prognostic value of steroid receptors after long-term follow-up of 2257 operable breast cancers. Br J Cancer 1996; 73: 1545-51.

[10] Parikh P, Palazzo JP, Rose LJ, et al. GATA-3 expression as a predictor of hormone response in breast cancer. J Am Coll Surgeons 2005; 200(5): 705-10.

[11] Perry MC. The chemotherapy source book: Breast Cancer. $4^{\text {th }}$ ed. Lippincott Williams \& Wilkins 2008; p. 365.

[12] Dressman MA, Walz TM, Lavedan C, et al. Genes that co-cluster with estrogen receptor alpha in microarray analysis of breast biopsies. Pharmacogenom J 2001; 1: 135-41.

[13] Elledge R, Green S, Pugh R, et al. Estrogen receptor (ER) and progesterone receptor $(\mathrm{PgR})$, by ligand-binding assay compared with $\mathrm{ER}, \mathrm{PgR}$ and $\mathrm{pS} 2$, by immunohistochemistry in predicting response to tamoxifen in metastatic breast cancer: a southwest oncology group study. Int J Cancer (Pred Oncol) 2000; 89: 111-7.

[14] Hoque MO, Feng Q, Toure P, et al. Detection of aberrant methylation of four genes in plasma DNA for the detection of breast cancer. J Clin Oncol 2006; 24: 4262-9.

[15] Efstathiou JA, Noda M, Rowan A, et al. Intestinal trefoil factor controls the expression of the adenomatous polyposis coli-catenin and the E-cadherin complexes in human colon carcinoma cells. Proc Natl Acad Sci USA 1998; 95: 3122-7. 
[16] May FE, Westley BR. Expression of human intestinal trefoil factor in malignant cells and its regulation by oestrogen in breast cancer cells. J Pathol 1997; 182: 404-13.

[17] Boersma BJ, Reimers M, et al. A stromal gene signature associated with inflammatory breast cancer. Int J Cancer 2008; 122(6): 132432.

[18] Desmedt C, Piette F, Loi S, et al. Strong time dependence of the 76-gene prognostic signature for node-negative breast cancer patients in the TRANSBIG multicenter independent validation series. Clin Cancer Res 2007; 13(11): 3207-14.

[19] Minn AJ, Gupta GP, Siegel PM, et al. Genes that mediate breast cancer metastasis to lung. Nature 2005 ; 436(7050): 518-24.

[20] Sotiriou C, Wirapati P, Loi S, et al. Gene expression profiling in breast cancer: understanding the molecular basis of histologic grade to improve prognosis. J Natl Cancer Inst 2006; 98(4): 262-72.

[21] Wang Y, Klijn JG, Zhang Y, et al. Gene-expression profiles to predict distant metastasis of lymph-node-negative primary breast cancer. Lancet 2005; 365(9460): 671-9.

[22] Ilyas M. Adhesion molecule expression in breast cancer: the phoenix in tumour metastasis? J Pathol 2000; 190(1): 3-5.

[23] Kohno M, Hasegawa H, Miyake M, et al. CD151 enhances cell motility and metastasis of cancer cells in the presence of focal adhesion kinase. Int J Cancer 2002; 97: 336-43.

[24] Ang J, Lijovic M, Ashman LK, et al. CD151 protein expression predicts the clinical outcome of low-grade primary prostate cancer better than histologic grading: a new prognostic indicator? Cancer Epidemiol Biomarkers Prev 2004; 13: 1717-21.
[25] Hashida H, Takabayashi A, Tokuhara T, et al. Clinical significance of transmembrane 4 superfamily in colon cancer. Br J Cancer 2003; 89: $158-67$.

[26] Tokuhara T, Hasegawa $\mathrm{H}$, Hattori N, et al. Clinical significance of CD151 gene expression in non-small cell lung cancer. Clin Cancer Res 2001; 7: 4109-14.

[27] Yang XH, Richardson AL, Torres-Arzayus MI, et al. CD151 accelerates breast cancer by regulating $\alpha_{6}$ integrin function, signaling, and molecular organization. Cancer Res 2008; 68: 320413.

[28] Miller JR. The Wnts. Genome Biol 2001; 3: 1-8.

[29] Karim R, Tse Q, Putti T, et al. The significance of the Wnt pathway in the pathology of human cancers. Pathology 2004; 36 $120-8$.

[30] Mikels AJ, Nusse R. Wnts as ligands: processing, secretion and reception. Oncogene 2006; 25: 7461-8.

[31] Turashvili G, Bouchal J, Burkadze G, et al. Wnt signaling pathway in mammary gland development and carcinogenesis. Pathobiology 2006; 73(5): 213-23.

[32] Brown AMC. Wnt signaling in breast cancer: have we come full circle? Breast Cancer Res 2001; 3: 351-5.

[33] Katoh M. Differential regulation of WNT2 and WNT2B expression in human cancer. Int J Mol Med 2001; 6(8): 657-60.

[34] Lin SY, Xia W, Wang JC, et al. Beta-catenin, a novel prognostic marker for breast cancer: its roles in cyclin D1 expression and cancer progression. Proc Natl Acad Sci USA 2000; 97: 4262-6.

[35] Hoch RV, Thompson DA, Baker RJ, et al. GATA-3 is expressed in association with estrogen receptor in breast cancer. Int $\mathrm{J}$ Cancer 1999; 84: $122-8$

(C) Zakaria et al.; Licensee Bentham Open.

This is an open access article licensed under the terms of the Creative Commons Attribution Non-Commercial License (http://creativecommons.org/licenses/by-nc/ $3.0 /$ ) which permits unrestricted, non-commercial use, distribution and reproduction in any medium, provided the work is properly cited. 